\section{A saúde dos trabalhadores da saúde em foco}

\author{
Adriane Mesquita de Medeiros*
}

MACHADO, Jorge Huet; ASSUNÇÃO, Ada Ávila (Orgs.). Panorama da saúde dos trabalhadores da saúde. Belo Horizonte: Faculdade de Medicina/Departamento de Medicina Preventiva e Social, da Universidade Federal de Minas Gerais - UFMG, 2012. 164p.

Publicado em 2012, o livro Panorama da saúde dos trabalhadores da saúde foi organizado por Jorge Huet Machado e Ada Ávila Assunção, que possuem expertise no assunto e também publicaram artigos em periódicos, além de outras obras e capítulos de livros referentes à temática explorada nesta publicação.

O livro possui cinco capítulos com a participação de diversos autores que apresentam fundamentações teóricas, metodológicas e operacionais relacionadas às condições de trabalho e de saúde dos trabalhadores da saúde. De forma sintética, a obra se inicia explicitando como se dá o processo de trabalho no campo da vigilância em saúde do trabalhador da saúde. Em seguida, são discutidos outros assuntos, como situações rotineiras vivenciadas pelos trabalhadores da saúde, necessidade de criação e implementação de estratégias direcionadas à qualidade do trabalho e promoção da saúde, abordagens teórico-metodológicas sobre a saúde e o adoecimento do trabalhador da saúde. A obra é finalizada com a apresentação de possibilidades de organização da vigilância em saúde do trabalhador.
No primeiro capítulo - "Vigilância em saúde do trabalhador da saúde" -, da autoria de Simone Santos Oliveira, Jorge Mesquita Huet Machado, Luciana de Assis Amorim e Roberta Alamonica de Oliveira, traçaram-se a história e concepção ampliada da vigilância em saúde do trabalhador, os instrumentos legais e normativos referentes às suas ações e os desafios a serem superados para sua operacionalidade dentro das práticas de saúde em geral. Os autores identificam os avanços significativos no campo conceitual e na ampliação dos recursos legais e destacam as fragilidades da aplicação da legislação e da regulação das condições relativas à saúde dos trabalhadores.

Maria Elizabeth Barros e Barros, Serafim Barbosa Santos Filho e Rafael da Silveira Gomes, no capítulo dois ("Alguns conceitos articulados na discussão do processo de trabalho em saúde"), ressaltam a necessidade de criação de instrumentos para o planejamento de ações visando a promoção da saúde, que foram reafirmadas pelas diretrizes da recente Política Nacional de Promoção da Saúde do Trabalhador do Sistema Único de Saúde - SUS (Protocolo 008/2011). Os conceitos de trabalho, processo de produção, cargas de trabalho, serviço, tecnologia, gestão, transdisciplinaridade, entre outros, foram trabalhados como vias para a transformação da realidade e reversão de situações desencadeadoras e agravadoras de problemas de saúde em trabalhadores. A Política Nacional de Humanização da Atenção e Gestão em Saúde (PNH) foi utilizada para a discussão dos conceitos de transversalidade, coletivo e subjetividade. Um ponto importante apresentado foi a necessidade de um esforço coletivo, que às vezes extrapola o setor saúde, em prol de mudanças concretas e reais nos locais de trabalho.

A revisão da produção nacional publicada entre 1996 e 2011, sobre a saúde dos trabalhadores do Sistema Único de Saúde (SUS), próprios e contratados, foi realizada

\footnotetext{
* Fonoaudióloga, doutora em Saúde Pública pela Universidade Federal de Minas Gerais.
} 
por Jussara Brito, Paulo Gilvane Lopes Pena, Luciana Gomes, Alice Paiva Souto e Armando Cypriano Pires, no capítulo três, intitulado "A saúde dos trabalhadores da saúde: focos, abordagens e estratégias de pesquisa". Os resultados foram analisados dentro dos seguintes contextos: hospital e serviços de urgência e emergência; unidades de terapia intensiva; estratégia saúde da família; unidades básicas de saúde e centros de saúde; e serviços de saúde mental. Os principais focos temáticos, de acordo com os serviços de saúde, foram a exposição à violência, as cargas de trabalho e o cotidiano de trabalho e seus desafios. Limites e avanços quanto aos métodos adotados foram descritos, indicando lacunas a serem preenchidas em futuras investigações. A combinação de métodos e técnicas foi ressaltada como estratégia que alcançou os melhores resultados.

Ada Ávila Assunção, Isabela Rodrigues Tavares e Paula Januzzi Serra realizaram uma revisão sistemática da literatura, abrangendo artigos em português, inglês e espanhol, publicados no período de 2007 a 2011, no capítulo 4 intitulado "Natureza e condições atuais do trabalho em saúde: o que diz a literatura sobre o adoecimento dos trabalhadores?". Vale ressaltar, neste capítulo, as evidências científicas sobre satisfação do trabalhador da saúde e autoavaliação de saúde, que sofrem a influência da estrutura organizacional e dos modelos de gestão e de atenção, devendo ser consideradas indicadores da qualidade dos serviços. Foram abordados os acidentes de trabalho e a exposição a material biológico e agentes infecciosos e algumas morbidades como a síndrome de burnout, transtornos mentais comuns, bem como sintomas musculoesqueléticos. A revisão mostra que os trabalhadores em saúde estão doentes e/ou sofrem acidentes de trabalho no exercício da profissão e revela o quanto o processo de trabalho, neste setor, tem sido negligen- ciado. Os dois capítulos de revisão tecem o panorama atual do processo saúde-doença e das condições de trabalho dos trabalhadores da saúde e foram sustentados pelos elementos históricos, políticos e conceituais expostos nos dois primeiros capítulos.

"Proposta de uma matriz de vigilância em saúde do trabalhador da saúde" é o título do último capítulo, da autoria de Jorge Mesquita Huet Machado, e evidencia as singularidades do trabalho neste setor, em que aspectos éticos e de responsabilidade social são inerentes ao cotidiano das atividades realizadas. $\mathrm{O}$ autor apresenta uma proposta desafiadora por meio da organização de uma matriz dinâmica e estruturante das interligações entre o processo de trabalho representado pela atividade e suas interfaces com os polos saúde, território e vulnerabilidade da vigilância em saúde do trabalhador. Traça-se uma possibilidade de transformação da determinação social da atividade de trabalho no sentido da promoção da saúde.

O livro contemplou um referencial teórico amplo e atual, com diversos constructos essenciais para a abordagem dos temas destacados. Os capítulos ressaltam as múltiplas repercussões que a atividade laboral exerce na saúde do trabalhador da saúde e concebem o trabalho como um constructo multifacetado e dinâmico, inserido num contexto social, econômico e cultural. A linguagem clara e concisa da obra é acessível ao trabalhador da saúde, pesquisador da área, professor universitário e estudantes, além de outros interessados no campo da saúde do trabalhador, que se constitui em objeto de estudo cada vez mais desafiador. Finalmente, salienta-se que a obra amplia a reflexão sobre os avanços das políticas públicas, métodos e conceitos no campo da saúde do trabalhador, apresentando, desse modo, caminhos e estratégias que precisam ser incorporados para se estabelecer um trabalho saudável no setor saúde.

Recebido para publicação em 13/09/2012

Aceito para publicação em 14/10/2012 